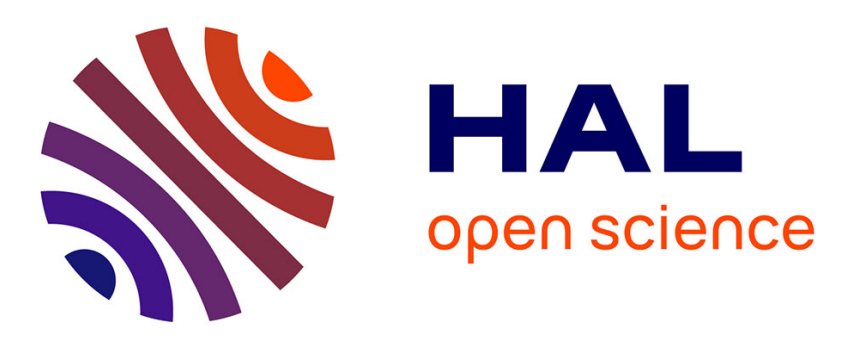

\title{
Temporal trends in retinal detachment incidence in Scotland between 1987 and 2006
}

Danny Mitry, James Chalmers, Kirsty Anderson, Linda Williams, Brian Fleck, Alan Wright, Harry Campbell

\section{- To cite this version:}

Danny Mitry, James Chalmers, Kirsty Anderson, Linda Williams, Brian Fleck, et al.. Temporal trends in retinal detachment incidence in Scotland between 1987 and 2006. British Journal of Ophthalmology, 2010, 95 (3), pp.365. 10.1136/bjo.2009.172296 . hal-00567045

\section{HAL Id: hal-00567045 https://hal.science/hal-00567045}

Submitted on 18 Feb 2011

HAL is a multi-disciplinary open access archive for the deposit and dissemination of scientific research documents, whether they are published or not. The documents may come from teaching and research institutions in France or abroad, or from public or private research centers.
L'archive ouverte pluridisciplinaire HAL, est destinée au dépôt et à la diffusion de documents scientifiques de niveau recherche, publiés ou non, émanant des établissements d'enseignement et de recherche français ou étrangers, des laboratoires publics ou privés. 


\section{Temporal trends in retinal detachment incidence in Scotland between 1987 and 2006}

Danny Mitry ${ }^{1,2}$, James Chalmers ${ }^{3}$, Kirsty Anderson ${ }^{3}$, Linda Williams ${ }^{2}$, Brian W. Fleck $^{1}$, Alan Wright ${ }^{4}$, Harry Campbell ${ }^{2}$

Correspondence to:

Dr. Danny Mitry M.B. B.Ch.

Clinical Research Fellow

Princess Alexandra Eye Pavilion

Edinburgh

EH3 7DH

Tel: +4478 188685332

Email: mitryd@gmail.com

Keywords - Epidemiology, Retinal detachment, Incidence

Manuscript word count $-2,144$

Abstract word count - 250

The Corresponding Author has the right to grant on behalf of all authors and does grant on behalf of all authors, an exclusive licence (or non-exclusive for government employees) on a worldwide basis to the BMJ Publishing Group Ltd and its Licensees to permit this article (if accepted) to be published in BJO and any other BMJPGL products to exploit all subsidiary rights, as set out in our licence (http://bjo.bmj.com/ifora/licence.pdf).

No author has any financial or proprietary interest in any product mentioned. Competing interests: None declared.

1 - Princess Alexandra Eye Pavilion, Edinburgh, EH3 7DH

2 - Department of Public Health Sciences, Teviot Place, University of Edinburgh

3 - Information Services Division of NHS National Services Scotland, 1 South

Gyle Crescent, Edinburgh EH12 9EB

4 - MRC Human Genetics Unit, Crewe Road, Edinburgh 


\section{Abstract}

\section{Aim}

Rhegmatogenous retinal detachment (RRD) is a common and sight threatening condition. RRD incidence has varied considerably in published literature and few studies have examined the temporal trends in incidence rate over a long time period. Our aim is to examine the time trends of primary RRD in Scotland.

\section{Methods}

We obtained linked hospital episode statistics data for all patients admitted with a primary diagnostic code of RRD in Scotland between 1987 to 2006 . Using this database as an estimate of RRD incidence, we calculated the annual age and sex specific incidence rates of RRD in Scotland. Loglinear Poisson regression analysis was used to explore age, period and cohort trends.

\section{Results}

The overall age standardised incidence of RRD in Scotland has steadily increased from 9.36 per 100,000 (95\%CI:8.19-10.53) in 1987 to 13.61 per 100,000 (95\%CI:12.25-14.97) in 2006 with an average annual increase of $1.9 \%$ $(p<0.001)$ during the 20-year period. Males have been affected more frequently than females in all age groups with a significant temporal trend towards earlier age of onset. The peak incidence of RRD in men and women is in the $6^{\text {th }}$ decade. No significant period or recent birth cohort trend effects were found.

\section{Conclusions}

The estimated incidence of RRD is within the range reported from previous population-based studies worldwide. The rise in RRD incidence between 1987 and 2006 is attributed in part to the changing demographic in Scotland. There is an increasing gender imbalance in incidence, with males being affected more frequently and at a younger age. 


\section{Introduction}

Rhegmatogenous retinal detachment (RRD) is a potentially blinding ophthalmic condition, the treatment of which is often complex and performed in specialised centres. The condition affects approximately 10-20 people in 100,000 annually ${ }^{1}$; the incidence increasing significantly with age and severity of myopia. ${ }^{2}$ Other risk factors influencing the incidence of RRD include ocular trauma, ethnic group and previous cataract surgery. ${ }^{3-7}$

An accurate epidemiology study requires high case ascertainment from a stable, well defined population that actively seeks medical care. Because of this, few studies have systematically examined the changes and influences on the incidence rate of RRD across different time periods in a well defined geographic area. There are six vitreo-retinal surgical sites in Scotland which are responsible for diagnosing and managing all RRD cases. The stable population structure and well defined referral and treatment patterns make Scotland an ideal region to conduct an epidemiology study.

The aim of our study is to examine the trends in RRD incidence in Scotland between 1987 and 2006, taking into account changes in the size and composition of the population over this period and examining the effect of age, calendar period and birth cohort on RRD incidence.

\section{Methods \\ Data Source}

The Information and Statistics Division of the Scottish Executive (ISD) is Scotland's national organisation for health information and statistics. They are responsible for National Health Service (NHS) hospital episode statistics data which comprise administrative, demographic and medical information on all inpatient and day-case procedure hospital episodes in all general and acute wards in Scotland. Private patients are not included in this database. These data are collected in hospital by trained clerical staff who assign diagnostic codes for each admission at the time of patient discharge. The information is transferred to the Information and Statistics Division of the Scottish Executive who collate and analyse the data.

Since 1987 these data have been linked to successive episodes of care for each person, so that individuals can be traced through multiple episodes of care. This record linkage is done through a probability matching algorithm. Firstly, to determine which record pairs belong to the same person, the records are matched by a Soundex/NYSIIS code (a name compression algorithm), first initial, sex, and date of birth. If there is a discrepancy in any one of these, the records will not be matched. Secondly, probability weights are calculated and applied to determine the likelihood that the records are from the same individual. This logarithmic weighting is based upon demographic criteria including surname, maiden name, sex, date of birth, residential postcode and other correspondence criteria such as date of admission and date of discharge. Once the probability weights are ordered, the threshold (defining linkage) is set, usually at the $50 / 50$ point. This is an automated process, with larger groups of records contributing to a higher false positive rate. Clerical monitoring of record pair batches estimate both the false positive and false negative rates from this process to be approximately $3 \% .^{8}$ 


\section{Statistical Methods}

We first used a log-linear regression model to examine the trends in RRD incidence and calculated an average annual percent change (AAPC) in incidence rate over the study period. A second order model with a quadratic trend term was also constructed to examine for possible non-linear trends. (Table $1 \mathrm{~A}$ )

We then used age-period-cohort modelling to explore the effects of chronological age, time period, and birth cohort on incidence trends. Individual data was grouped into eighteen 5-year age groups from 0-4 years through to $85+$ years, four 5-year calendar periods from 1987-1991 through to 2002-2006 and twenty derived birth cohorts. Assuming a Poisson distribution of cases of RRD, a loglinear regression model was used to estimate the changes in RRD incidence by age, period and birth cohort. (SPSS v16) The Poisson model used took the form of:

$$
-\log (\text { rate })=\mu+a_{i}+\beta_{j}+\gamma_{k}+\varepsilon_{i j k}
$$

Where $a_{i}$ is the age effect, $\beta_{j}$ is the period effect and $\gamma_{k}$ is the cohort effect. The term $\varepsilon_{\mathrm{ijk}}$ is the random error term. The parameter estimates were calculated as maximum likelihood estimates. We assigned the first period (1987-1991) and last age group (85+) as reference groups. Based on this general form, we established 5 models in sequence: a one-factor age model, a two-factor age-drift model, age-cohort model, age-period model, and an age-period-cohort model. The drift term in the age-drift model represents a temporal change in incidence rate not identifiable as a period or cohort effect. (Table 2) We calculated goodness of fit (R-squared) statistics to determine the model accounting for the most variability. The full age-period-cohort model had the lowest residual deviance and an $\mathrm{R}^{2}$ of 0.96 and was used in the analysis.

Age and sex-specific incidence rates of patients admitted with a first diagnosis of RRD in Scotland were calculated annually. Annual incidence rates were calculated on the basis that the first admission only counted toward the episode rate, so that recurrent individual admissions with the same diagnostic code were not counted after the first admission. This method aims to eliminate re-operations on RRD cases; however, consecutive bilateral RRD cases will only have been counted once. Age and sex standardised rates were calculated by a direct method using the European Standard Population as a reference. Annual population data was obtained from the General Register Office for Scotland from the Scottish population censuses since 1987. Using the 1987 age specific incidence rate and the 2006 population census, we calculated the expected standardised incidence rate for each age group in 2006 and compared this to the observed incidence rates in 2006.

The diagnostic codes used to identify patients with RRD were $361.0-361.9$ and 362.4 in the International Classification of Disease $9^{\text {th }}$ edition (ICD-9) and H33.0 -33.5 in ICD-10. Over the analysis period, coding of RRD changed between ICD9 and ICD-10, however no corresponding change in hospital admission rates was noted during this changeover period (between 1994 and 1995).

\section{Results}

The age specific and age standardised annual RRD incidence rate between 1987 and 2006 is shown in table 3. The crude incidence rate of RRD for all ages and both genders rose steadily from 10.06 per 100,000 (95\%CI: $9.19-10.93$ per 
100,000 ) in 1987 to 15.28 per 100,000 ( $95 \% \mathrm{CI}: 14.21-16.35$ per 100,000 ) in 2006. The incidence of RRD was higher in males of all age groups, and the temporal rise in incidence was more marked in males. The age standardised male:female incidence ratio rose from 1.40 in 1987 to 1.76 in $2006 .(p<0.001)$ Figure 1 demonstrates the age and sex specific RRD rates for men and women over the 20 year period. Both genders showed a significant rising trend in the highest incidence age groups (60-79 years). In men, the strongest rising trend in incidence was found in younger age groups between 40 to 59 years, a pattern which was absent in females.

The average annual percent change (AAPC) in RRD incidence increased annually by $1.9 \%$ overall in the 20 year period. Significant increases were noted in nearly all age groups with the exception of those under 20 years and in the 30-39 year age group. (Table $1 \mathrm{~A}$ ) The second order quadratic trend term did not demonstrate a significant change in incidence, with the exception of the over 80 year age group.

We calculated the expected age specific incidence rate in 2006 using the 1987 age specific rate standardised to the 2006 Scottish population and compared this to the observed age specific rate in 2006. (Table 1B) The observed rate in 2006 was significantly higher than the expected rate in all age groups over 40 years. Figure 2 demonstrates the combined age-period-cohort effects on RRD incidence. Chronological age demonstrates a bimodal distribution in incidence with a peak in the sixth decade, as well as a secondary smaller peak in the $3^{\text {rd }}$ decade. No significant period effects were found. No significant birth cohort effects were found in cohorts since 1940. Prior to this there was a reduction in risk ratio (0.25-0.86) as fewer parameters were available for analysis.

\section{Discussion}

Retrospective hospital episode statistics (HES) data which we have used to estimate disease incidence have some limitations, $9 ; 10$ including insufficient clinical details, incorrect diagnostic coding, duplicate entries and incomplete population coverage. Thus the use of HES to estimate disease incidence is by necessity an approximation and often limits the ability of the investigator to examine other influencing aspects of disease, such as in our case, the prevalence of myopia or ocular trauma. However HES remain a useful indicator of changing incidence trends, particularly where the study population is a stable one actively seeking medical care and the disease under investigation requires hospital admission for treatment.

ISD Data used in this study is derived from hospital episode statistics, the accuracy of which is dependent on appropriate and exact coding. A recent quality control audit of surgical specialties (excluding general surgery) indicates coding for main condition is accurate in 88.5\% (95\%CI: 86.3-90.7) and for main operation in $93 \%$ (95\% CI: 91.2-94.8). ${ }^{9}$ The proportion of RRD cases treated in the private sector is unknown, however we expect this number to be very low, as elective eye operations in England and Wales in 1998 (excluding cataract extraction) accounted for only $1.8 \%$ of all eye operations performed in NHS hospitals. ${ }^{11}$ This relevant proportion is likely to be lower in Scotland as RRDs diagnosed and followed-up privately will be operated on in NHS hospitals. 
The overall crude incidence rate of RRD worldwide from studies of adequate methodology has been reported between 6.3 and 17.9 per 100,000 of population $1 ; 4 ; 5 ; 7 ; 12-17$, however, many studies do not report the standardised incidence rates and have not examined incidence trends over a long time period, making it difficult to determine if the rise in incidence noted in Scotland is also present in other populations. Based on HES data, the estimated age standardised incidence rate of RRD in Scotland was 13.61 per 100,000 of population in 2006.

Over 20 years, we have observed a significant average annual percent increase in RRD incidence of $1.9 \%$. A proportion of this increase in incidence is attributable to temporal changes in the Scottish population and the rising proportion of elderly individuals. However, the statistically significant difference noted between the expected and observed incidence rates in 2006 suggests that there are other factors which may have influenced the trend observed. The proportion of myopia, previous cataract surgery, ocular trauma and the socioeconomic status of a study population can all affect RRD incidence. ${ }^{18 ; 19}$ Temporal changes in the prevalence of these risk factors in Scotland are likely to also contribute to the observed trend in incidence. Furthermore, the advances in vitreo-retinal surgery and the expansion of specialist vitreo-retinal services in Scotland between 1987 and 2006, may have increased the number of operable cases and subsequently contributed to the rise in disease incidence noted.

The incidence of RRD in both men and women peaks in the $6^{\text {th }}$ decade with a secondary peak in the $3^{\text {rd }}$ decade, which is widely supported by previous population based estimates. ${ }^{4 ; 5 ; 7 ; 12-17}$ Examining sex-specific RRD rates over 20 years, we found a higher incidence in males in virtually all age groups with an age standardised male:female incidence ratio varying between 1.31:1 to 1.82:1. The higher incidence in men has been reported in previous studies with male:female incidence ratios varying between $1.3: 1$ to $2.3: 1.5 ; 6 ; 14 ; 20 ; 21$ This gender imbalance in RRD incidence in our study cannot be explained by the underlying gender distribution of the Scottish population and a higher rate of traumatic RRD in men or an inherent increased risk in males may be contributory. ${ }^{3 ; 22}$

We also note a temporal trend towards an earlier age of onset in males. There is a significant increase in RRD incidence in males of younger age groups (40-59 years) across the 20 year study period when compared to females of similar age. The reason for this is uncertain, but may be due to differences in the levels of myopia between genders or due to lifestyle differences, where males may under-report 'minor' ocular trauma. Previous studies have indicated that in younger myopic populations, males tend to predominate ${ }^{23-28}$, and in certain populations the influence of myopia, axial length and cataract surgery in males confers a higher risk for RRD development when compared with females. ${ }^{22}$

An accurate estimate of disease incidence is an important first step in assessing the related healthcare burden. Our results from national hospital episode data in Scotland over a 20-year period indicate a higher age standardised incidence in males and an increasing incidence of RRD in both sexes. The rise in RRD incidence was more notable in males of all ages with a trend towards earlier age of onset. This increase in RRD incidence may be partly attributed to the aging population in Scotland over the study period but other contributing factors may also exist. With the changes in population structure and a longer living population, it is likely that RRD will continue to add to the burden on ophthalmic services in Scotland. 
This work is supported by a grant from the Royal College of Surgeons Edinburgh

\section{Legend:}

Table 1A - Age specific average annual percent change (AAPC) of RRD incidence in Scotland between 1987-2006.

Table 1B - The age specific expected and observed incidence of RRD in 2006 calculated using the 1987 age specific incidence rate standardised with the 2006 Scottish population.

Table 2 - Summary statistics comparing the goodness of fit for different ageperiod-cohort models. The 'drift' parameter represents a log-linear change in rate that is not identifiable as a period or cohort effect. P-values are based on the F-test comparison. The two-factor models (age-cohort and age-period) were examined in comparison to age-drift, and the age-period-cohort model was examined in comparison to the two-factor age-cohort model.

Table 3 - The annual incidence of RRD by age group and the age standardised incidence in men and women between 1987-2006. This table highlights the increasing incidence of RRD and demonstrates the much higher age standardised incidence in men.

Figure 1A - Age sepcific and standardised incidence of RRD in men. A signficant rising trend was found in all age groups combined $\left(x^{2}\right.$ trend $=154.96, p$-value $<$ $0.001)$ and in age groups $40-59$ years $\left(x^{2}\right.$ trend $=71.43, p$-value $\left.<0.001\right)$ and $60-79$ years $\left(x^{2}\right.$ trend $=42.22$, $p$-value $\left.<0.001\right)$.

Figure 1B - Age sepcific and standardised incidence of RRD in women. A signficant rising trend was found in all age groups combined $\left(x^{2}\right.$ trend $=27.84, p$ value $<0.001)$ and in age group 60-79years only $\left(x^{2}\right.$ trend $=12.35, p$-value $<$ $0.001)$.

Figure 2 - Age-period-cohort plot of parameter estimates and associated 95\% confidence intervals of RRD incidence in Scotland. This figure highlights the increasing incidence of RRD with age, demonstrating a peak in the $6^{\text {th }}$ decade and a smaller secondary peak in the $3^{\text {rd }}$ decade. No significant period effects were noted. There were no significant effects in recent birth cohorts. 


\begin{tabular}{|c|c|c|c|c|c|c|c|c|c|}
\hline \multirow[t]{2}{*}{ (A) } & \multirow[b]{2}{*}{ Age } & \multicolumn{2}{|c|}{ Linear model } & \multicolumn{2}{|c|}{ Quadratic trend term } & \multirow[t]{2}{*}{ (B) } & \multirow[b]{2}{*}{ Age } & \multicolumn{2}{|c|}{$\begin{array}{l}\text { Incidence per } 100,000 \text { population } \\
\text { ( } 95 \% \text { Confidence Interval) }\end{array}$} \\
\hline & & AAPC (\%) & p-value & $\begin{array}{l}\text { Sign of } \\
2^{\text {nd }} \text { order } \\
\text { term }\end{array}$ & p-value & & & $\begin{array}{l}\text { Expected } 2006 \\
\text { Incidence }\end{array}$ & $\begin{array}{l}\text { Observed } 2006 \\
\text { Incidence }\end{array}$ \\
\hline & $0-9$ & +1.1 & 0.588 & + & 0.066 & & $0-9$ & $0.91(0.3-2.1)$ & $1.64(0.8-3.1)$ \\
\hline & 10-19 & -1.2 & 0.166 & + & 0.194 & & 10-19 & $4.45(2.9-6.4)$ & $3.14(1.9-4.8)$ \\
\hline & 20-29 & +1.1 & 0.049 & - & 0.176 & & $20-29$ & $6.92(5.1-9.3)$ & $6.77(4.9-9.1)$ \\
\hline & $30-39$ & +0.2 & 0.619 & + & 0.782 & & $30-39$ & $7.98(6-10.4)$ & $9.12(7-11.6)$ \\
\hline & 40-49 & +1.2 & 0.04 & - & 0.057 & & $40-49$ & $7.40(5.6-9.6)$ & $13.28(10.9-16.1)$ \\
\hline & 50-59 & +2.6 & $<0.001$ & - & 0.915 & & $50-59$ & $12.49(10-15.5)$ & $27.64(23.8-31.9)$ \\
\hline & 60-69 & +1.9 & $<0.001$ & - & 0.474 & & $60-69$ & $22.94(19-27.4)$ & $34.42(29.6-39.8)$ \\
\hline & 70-79 & +1.6 & 0.001 & - & 0.951 & & 70-79 & $30.72(25.4-36.8)$ & $35.18(29.5-41.7)$ \\
\hline & $80+$ & +1.9 & 0.019 & - & 0.001 & & $80+$ & 13.56(9.1-19.5) & $18.24(13-24.9)$ \\
\hline & $\begin{array}{l}\text { All } \\
\text { ages }\end{array}$ & +1.9 & $<0.001$ & - & 0.334 & & All ages & $10.61(9.7-11.5)$ & $15.28(14.2-16.4)$ \\
\hline
\end{tabular}

Table 1A - Age specific average annual percent change (AAPC) of RRD incidence in Scotland between 1987-2006.

Table 1B - The age specific expected and observed incidence of RRD in 2006 calculated using the 1987 age specific incidence rate standardised with the 2006 Scottish population. 


\begin{tabular}{|l|l|l|l|l|}
\hline & Residual Deviance(Df) & Deviance (Df) & P- value & Adjusted R-squared \\
\hline Age & $1291.37(126)$ & & & \\
\hline Age-drift & $1216.9(125)$ & $74.47(1)$ & $<0.001$ & \\
\hline Age-Cohort & $1039.82(106)$ & $177.08(19)$ & $<0.001$ & 0.87 \\
\hline Age-Period & $1214.19(123)$ & $2.71(2)$ & 0.25 & 0.98 \\
\hline Age-Period-Cohort & $1034.1(104)$ & $5.72(2)$ & 0.044 & 0.96 \\
\hline
\end{tabular}

Table 2 - Summary statistics comparing the goodness of fit for different age-period-cohort models. The 'drift' parameter represents a log-linear change in rate that is not identifiable as a period or cohort effect. P-values are based on the F-test comparison. The two-factor models (age-cohort and age-period) were examined in comparison to age-drift, and the age-period-cohort model was examined in comparison to the two-factor age-cohort model. 
Age Group

\begin{tabular}{|c|c|c|c|c|c|c|c|c|c|c|c|c|c|}
\hline $\begin{array}{c}\text { Year of } \\
\text { Diagnosis }\end{array}$ & $0-9$ & $10-19$ & $20-29$ & $30-39$ & $40-49$ & 50-59 & $60-69$ & $70-79$ & $80+$ & $\begin{array}{l}\text { All Ages } \\
(95 \% \mathrm{CI})\end{array}$ & $\begin{array}{c}\text { Men } \\
(95 \% \mathrm{CI})\end{array}$ & $\begin{array}{l}\text { Women } \\
(95 \% \mathrm{CI})\end{array}$ & $\begin{array}{c}\text { M:F } \\
\text { Ratio }\end{array}$ \\
\hline 1987 & 0.94 & 4.36 & 6.92 & 7.92 & 7.36 & 12.50 & 23.02 & 30.65 & 13.38 & $\begin{array}{c}10.06 \\
(9.19-10.93)\end{array}$ & $\begin{array}{c}10.92 \\
(9.61-12.23)\end{array}$ & $\begin{array}{c}7.80 \\
(6.77-8.82)\end{array}$ & 1.40 \\
\hline 1988 & 1.09 & 5.84 & 5.28 & 8.24 & 10.42 & 19.33 & 25.24 & 23.08 & 16.68 & $\begin{array}{c}11.01 \\
(10.10-11.92)\end{array}$ & $\begin{array}{c}12.93 \\
(11.48-14.38)\end{array}$ & $\begin{array}{c}8.49 \\
(7.39-9.59)\end{array}$ & 1.52 \\
\hline 1989 & 1.08 & 3.67 & 7.00 & 8.45 & 11.48 & 18.44 & 28.09 & 26.81 & 13.16 & $\begin{array}{c}11.52 \\
(10.59-12.45)\end{array}$ & $\begin{array}{c}13.44 \\
(11.99-14.90)\end{array}$ & $\begin{array}{c}8.50 \\
(7.41-9.59)\end{array}$ & 1.58 \\
\hline 1990 & 0.93 & 2.70 & 7.03 & 8.87 & 11.15 & 19.93 & 28.12 & 28.91 & 17.09 & $\begin{array}{c}11.85 \\
(10.90-12.79)\end{array}$ & $\begin{array}{c}12.98 \\
(11.55-14.41)\end{array}$ & $\begin{array}{c}9.45 \\
(8.30-10.61)\end{array}$ & 1.37 \\
\hline 1991 & 0.47 & 3.69 & 5.49 & 8.43 & 10.20 & 16.47 & 28.95 & 25.39 & 17.86 & $\begin{array}{c}11.00 \\
(10.09-11.91)\end{array}$ & $\begin{array}{c}11.87 \\
(10.51-13.23)\end{array}$ & $\begin{array}{c}8.64 \\
(7.55-9.73)\end{array}$ & 1.37 \\
\hline 1992 & 0.62 & 3.60 & 7.17 & 9.21 & 12.96 & 17.21 & 28.78 & 27.11 & 17.52 & $\begin{array}{c}11.94 \\
(10.99-12.89)\end{array}$ & $\begin{array}{c}13.73 \\
(12.27-15.19)\end{array}$ & $\begin{array}{c}8.96 \\
(7.84-10.08)\end{array}$ & 1.53 \\
\hline 1993 & 1.08 & 3.33 & 6.91 & 9.68 & 10.89 & 21.36 & 34.51 & 28.53 & 23.34 & $\begin{array}{c}13.06 \\
(12.07-14.05)\end{array}$ & $\begin{array}{c}14.42 \\
(12.92-15.92)\end{array}$ & $\begin{array}{c}10.08 \\
(8.90-11.26)\end{array}$ & 1.43 \\
\hline 1994 & 0.62 & 3.50 & 7.58 & 8.19 & 10.92 & 20.43 & 30.92 & 35.81 & 14.27 & $\begin{array}{c}12.64 \\
(11.67-13.62)\end{array}$ & $\begin{array}{c}13.43 \\
(11.99-14.87)\end{array}$ & $\begin{array}{c}10.24 \\
(9.05-11.43)\end{array}$ & 1.31 \\
\hline 1995 & 0.16 & 3.18 & 7.41 & 8.68 & 13.98 & 21.04 & 30.40 & 32.59 & 22.07 & $\begin{array}{c}13.11 \\
(12.11-14.10)\end{array}$ & $\begin{array}{c}14.44 \\
(12.95-15.94)\end{array}$ & $\begin{array}{c}10.09 \\
(8.92-11.26)\end{array}$ & 1.43 \\
\hline 1996 & 0.79 & 4.13 & 6.15 & 10.27 & 11.94 & 21.24 & 26.51 & 28.07 & 22.57 & $\begin{array}{c}12.49 \\
(11.52-13.56)\end{array}$ & $\begin{array}{c}14.53 \\
(13.04-16.03)\end{array}$ & $\begin{array}{c}9.07 \\
(7.95-10.19)\end{array}$ & 1.60 \\
\hline 1997 & 0.96 & 3.62 & 8.99 & 7.43 & 13.09 & 21.14 & 28.72 & 35.40 & 22.20 & $\begin{array}{c}13.36 \\
(12.35-14.36)\end{array}$ & $\begin{array}{c}15.30 \\
(13.76-16.83)\end{array}$ & $\begin{array}{c}9.63 \\
(8.49-10.78)\end{array}$ & 1.59 \\
\hline 1998 & 0.65 & 3.43 & 7.43 & 8.16 & 11.90 & 20.11 & 35.58 & 27.55 & 24.65 & $\begin{array}{c}13.20 \\
(12.20-14.20)\end{array}$ & $\begin{array}{c}15.13 \\
(13.61-16.65)\end{array}$ & $\begin{array}{c}9.24 \\
(8.13-10.35)\end{array}$ & 1.64 \\
\hline 1999 & 1.48 & 3.11 & 9.18 & 8.67 & 12.51 & 19.72 & 29.54 & 32.99 & 26.04 & $\begin{array}{c}13.53 \\
(12.51-14.54)\end{array}$ & $\begin{array}{c}15.88 \\
(14.32-17.44)\end{array}$ & $\begin{array}{c}9.13 \\
(8.02-10.24)\end{array}$ & 1.74 \\
\hline 2000 & 0.67 & 2.34 & 6.72 & 8.23 & 12.49 & 23.22 & 30.49 & 30.58 & 24.99 & $\begin{array}{c}13.33 \\
(12.33-14.34)\end{array}$ & $\begin{array}{c}15.17 \\
(13.66-16.69)\end{array}$ & $\begin{array}{c}9.35 \\
(8.22-10.47)\end{array}$ & 1.62 \\
\hline 2001 & 0.52 & 2.34 & 8.09 & 6.37 & 9.62 & 20.75 & 35.53 & 34.07 & 22.06 & $\begin{array}{c}13.21 \\
(12.21-14.21)\end{array}$ & $\begin{array}{c}13.91 \\
(12.46-15.36)\end{array}$ & $\begin{array}{c}9.92 \\
(8.77-11.06)\end{array}$ & 1.40 \\
\hline 2002 & 0.88 & 4.99 & 7.27 & 9.58 & 12.86 & 25.00 & 34.31 & 31.86 & 24.02 & $\begin{array}{c}14.86 \\
(13.79-15.92)\end{array}$ & $\begin{array}{c}16.56 \\
(14.99-18.13)\end{array}$ & $\begin{array}{c}10.22 \\
(9.05-11.38)\end{array}$ & 1.62 \\
\hline 2003 & 1.26 & 3.57 & 7.33 & 9.63 & 13.55 & 26.89 & 38.25 & 32.54 & 19.30 & $\begin{array}{c}15.42 \\
(14.34-16.51)\end{array}$ & $\begin{array}{c}18.10 \\
(16.45-19.74)\end{array}$ & $\begin{array}{c}10.00 \\
(8.84-11.16)\end{array}$ & 1.81 \\
\hline 2004 & 0.54 & 3.71 & 9.24 & 8.23 & \begin{tabular}{|l|}
10.51 \\
\end{tabular} & 23.54 & 35.92 & 39.33 & 22.35 & $\begin{array}{c}14.97 \\
(13.90-16.03)\end{array}$ & $\begin{array}{c}16.81 \\
(15.24-18.38)\end{array}$ & $\begin{array}{c}9.91 \\
(8.77-11.04)\end{array}$ & 1.70 \\
\hline 2005 & 1.09 & 3.27 & 6.98 & 9.72 & 11.61 & 27.55 & 36.27 & 34.06 & 16.75 & $\begin{array}{c}15.07 \\
(14.01-16.14)\end{array}$ & $\begin{array}{c}17.57 \\
(15.96-19.17)\end{array}$ & $\begin{array}{c}9.67 \\
(8.73-11)\end{array}$ & 1.82 \\
\hline 2006 & 1.64 & 3.14 & 6.78 & 9.12 & 13.28 & 27.64 & 34.42 & 35.18 & 18.25 & $\begin{array}{c}15.28 \\
(14.21-16.35)\end{array}$ & $\begin{array}{c}17.35 \\
(15.77-18.93)\end{array}$ & $\begin{array}{c}9.87 \\
(8.83-11.11)\end{array}$ & 1.76 \\
\hline
\end{tabular}


Table 3 - The annual incidence of RRD by age group and the age standardised incidence in men and women between 19872006. This table highlights the increasing incidence of RRD and demonstrates the much higher age standardised incidence in men. 
Reference List

1. Mitry D, Charteris DG, Fleck BW et al. 'The Epidemiology of Rhegmatogenous Retinal Detachment - Geographic Variation and Clinical Associations'. Br J Ophthalmol 2009.

2. The Eye Disease Case-Control Study Group. Risk factors for idiopathic rhegmatogenous retinal detachment. Am.J Epidemiol. 1993;137:749-57.

3. Wong TY, Tielsch JM, Schein OD. Racial difference in the incidence of retinal detachment in Singapore. Arch Ophthalmol 1999;117:379-83.

4. Li X. Incidence and epidemiological characteristics of rhegmatogenous retinal detachment in Beijing, China. Ophthalmology 2003;110:2413-7.

5. Polkinghorne PJ, Craig JP. Northern New Zealand Rhegmatogenous Retinal Detachment Study: epidemiology and risk factors. Clin Experiment.Ophthalmol 2004;32:159-63.

6. Mowatt $L$, Shun-Shin G, Price N. Ethnic differences in the demand incidence of retinal detachments in two districts in the West Midlands. Eye 2003;17:63-70.

7. Wilkes SR, Beard CM, Kurland LT et al. The incidence of retinal detachment in Rochester, Minnesota, 1970-1978. Am J Ophthalmol 1982;94:670-3.

8. Information Services Division - Background to Record Linkage. http://www. isdscotland.org/isd/5053.html . 2008.

Ref Type: Electronic Citation

9. An Assessment of SMOR1 and associated data 2004-2006. NHS Scotland . 2007. Ref Type: Electronic Citation

10. Milburn JA, Driver CP, Youngson GG et al. The accuracy of clinical data: a comparison between central and local data collection. Surgeon. 2007;5:275-8.

11. Williams B, Whatmough $P$, McGill J et al. Private funding of elective hospital treatment in England and Wales, 1997-8: national survey. BMJ 2000;320:904-5.

12. Algvere PV, Jahnberg P, Textorius O. The Swedish Retinal Detachment Register. I. A database for epidemiological and clinical studies. Graefes Arch Clin Exp Ophthalmol $1999 ; 237: 137-44$.

13. Haimann MH, Burton TC, Brown CK. Epidemiology of retinal detachment. Arch Ophthalmol 1982;100:289-92.

14. Limeira-Soares PH, Lira RP, Arieta CE et al. Demand incidence of retinal detachment in Brazil. Eye 2007;21:348-52.

15. Rowe JA, Erie JC, Baratz KH et al. Retinal detachment in Olmsted County, Minnesota, 1976 through 1995. Ophthalmology 1999;106:154-9. 
16. Laatikainen L, Tolppanen EM, Harju H. Epidemiology of rhegmatogenous retinal detachment in a Finnish population. Acta Ophthalmol (Copenh) 1985;63:59-64.

17. Zou $\mathrm{H}$, Zhang $\mathrm{X}, \mathrm{Xu} X$ et al. Epidemiology survey of rhegmatogenous retinal detachment in Beixinjing District, Shanghai, China. Retina 2002;22:294-9.

18. Saidkasimova S, Mitry D, Singh J et al. Retinal detachment in Scotland is associated with affluence. Br J Ophthalmol 2009;93:1591-4.

19. Austin $\mathrm{KL}$, Palmer JR, Seddon JM et al. Case-control study of idiopathic retinal detachment. Int.J Epidemiol 1990;19:1045-50.

20. Ivanisevic $M$, Bojic $L$, Eterovic D. Epidemiological study of nontraumatic phakic rhegmatogenous retinal detachment. Ophthalmic Res 2000;32:237-9.

21. Rosman M, Wong TY, Ong SG et al. Retinal detachment in Chinese, Malay and Indian residents in Singapore: a comparative study on risk factors, clinical presentation and surgical outcomes. Int.Ophthalmol 2001;24:101-6.

22. Sheu SJ, Ger LP, Chen JF. Male sex as a risk factor for pseudophakic retinal detachment after cataract extraction in Taiwanese adults. Ophthalmology 2007; 114: 1898-903.

23. Hirsch MJ, Ditmars DL. Refraction of young myopes and their parents--a reanalysis. Am.J Optom.Arch.Am.Acad.Optom. 1969;46:30-2.

24. Hirsch M.J. Sex differences in the incidence of various grades of myopia. Am.J.Optom $1953 ; 30: 135-8$.

25. Bourne RR, Dineen BP, Ali SM et al. Prevalence of refractive error in Bangladeshi adults: results of the National Blindness and Low Vision Survey of Bangladesh. Ophthalmology 2004;111:1150-60.

26. Dandona $R$, Dandona $L$, Srinivas $M$ et al. Population-based assessment of refractive error in India: the Andhra Pradesh eye disease study. Clin. Experiment. Ophthalmol $2002 ; 30: 84-93$.

27. Sawada A, Tomidokoro A, Araie $M$ et al. Refractive errors in an elderly Japanese population: the Tajimi study. Ophthalmology 2008;115:363-70.

28. Attebo K, Ivers RQ, Mitchell P. Refractive errors in an older population: the Blue Mountains Eye Study. Ophthalmology 1999;106:1066-72. 


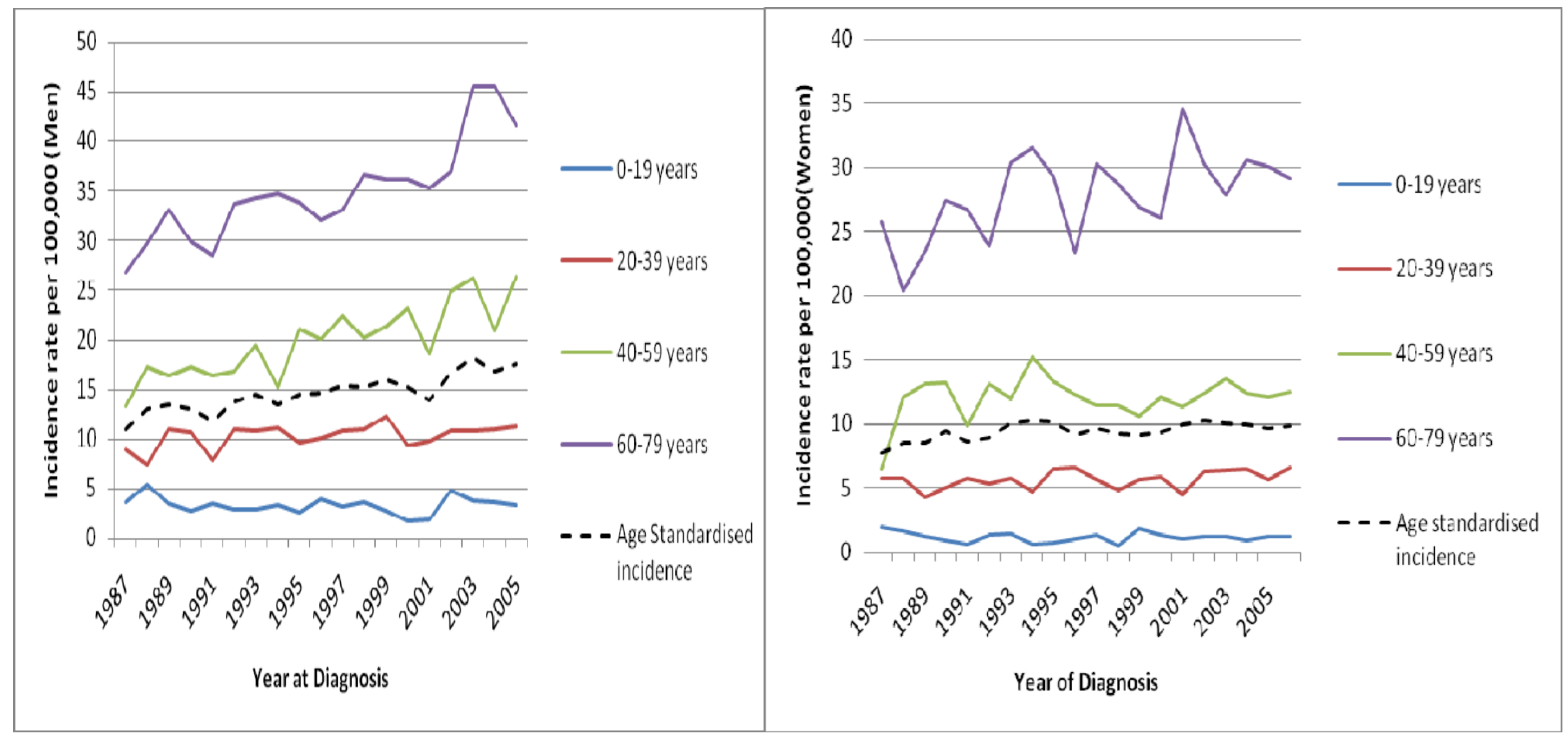




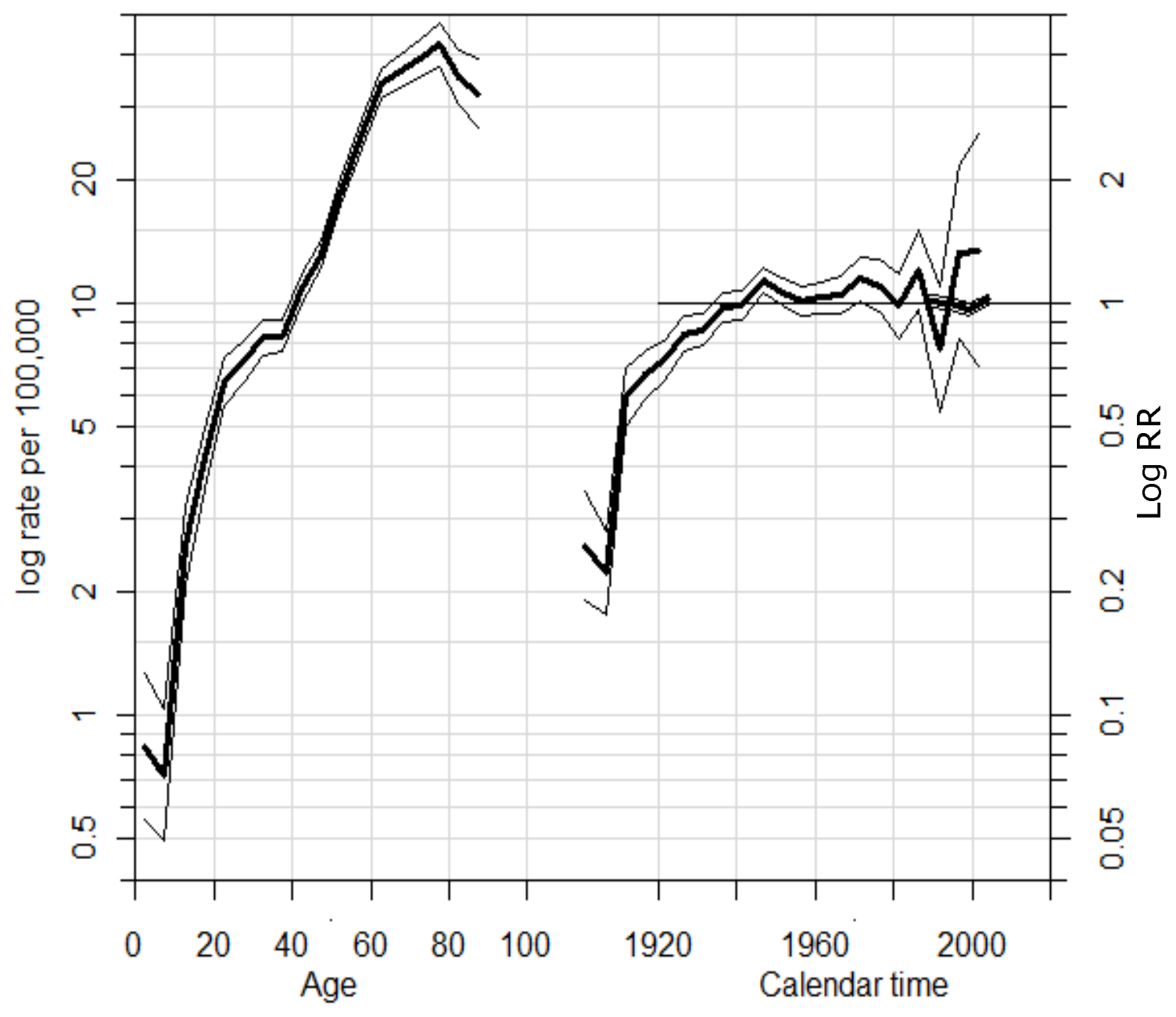

